\title{
Influence of microkeratome parameters on the stromal bed and flap edge quality in laser in situ keratomileusis
}

This article was published in the following Dove Press journal:

Clinical Ophthalmology

16 December 2013

Number of times this article has been viewed

Jens Heichel'

Frank Wilhelm²

Kathleen S Kunert ${ }^{3}$

Rabea Schlueter ${ }^{4}$

Ute Stuhltraeger'

Thomas Hammer ${ }^{5}$

'Department of Ophthalmology, University Hospital of Martin Luther University Halle/Wittenberg, Halle (Saale), Germany; ${ }^{2}$ Augen im

Zentrum, Greifswald, Germany;

${ }^{3}$ Department of Ophthalmology,

Helios Klinikum Erfurt, Erfurt,

Germany; ${ }^{4}$ Institute of Microbiology,

Ernst-Moritz-Arndt-University,

Greifswald, Germany;

${ }^{5}$ Augenzentrum Frohe Zukunft, Halle (Saale), Germany
Correspondence: Jens Heichel Department of Ophthalmology, University Hospital of Martin Luther University Halle/Wittenberg,

Ernst-Grube-Straße 40, 06120 Halle (Saale), Germany

Tel +49345 557 I 878

Fax +49 3455574620

Email jens.heichel@uk-halle.de
Purpose: Femtosecond lasers have become the standard for laser-assisted in situ keratomileusis (LASIK) flap creation, but advanced mechanical microkeratomes are still an alternative, more cost-effective way to create the flap. The SCHWIND Carriazo-Pendular microkeratome is one of the most commonly used microkeratomes. The influence of different cutting parameters (head-advance speeds, cutting heads) on morphology of LASIK cuts was investigated.

Setting: Experimental study performed at the University Eye Hospital of the Martin Luther University Halle/Wittenberg, Halle (Saale), Germany.

Methods: The Carriazo-Pendular microkeratome was used on freshly enucleated porcine eyes for lamellar keratotomy. After flap removal, the cutting edge and stromal bed were evaluated from scanning electron micrographs using an individualized scoring system. Four different settings of microkeratome parameters were compared. For each setting, eight cuts were evaluated $(n=32)$.

Results: Different oscillation frequencies and head-advance speeds did not influence the cutting qualities. A higher oscillation/feed rate ratio seemed to be advantageous for a smoother interface. Concerning different cuttings heads, a deeper keratotomy led to sharper cutting edges. The thinner the flap, the more irregularities in the stromal bed appeared. Complications did not occur.

Conclusion: The Carriazo-Pendular microkeratome is a safe tool with which to create a LASIK flap and is a good alternative to a costly femtosecond laser. Deeper keratotomies, as well as the use of a higher oscillation/feed rate quotient, improve the cutting quality.

Keywords: laser-assisted in situ keratomileusis (LASIK), microkeratome, stromal bed quality, surface regularity, Descemet's stripping automated endothelial keratoplasty (DSAEK), scanning electron microscopy (SEM)

\section{Introduction}

Laser-assisted in situ keratomileusis (LASIK) is a widely used technique in refractive corneal surgery. The procedure itself consists of different surgical steps. One of the important parts of this surgery is the flap creation. Many complications can occur during the preparation of the corneal flap, resulting in costly retreatments. A meta-analysis of 30 trials reported an incidence of $31 \%$ for intraoperative complications, of which 19\% were microkeratome associated. These were cutting failures such as buttonholes, free caps, or irregular or incomplete cuts. The complications required retreatments, comprising the majority of postoperative costs. ${ }^{1,2}$ Application of femtosecond lasers (fs-lasers) is safe and predictable. Nevertheless, specific complications, such as transient light sensitivity syndrome, rainbow glare, and complications concerning gas bubbles, 
may arise. Comparison studies are still being conducted comparing laser devices and mechanical microkeratomes. The laser devices have been found to be as good as or better than mechanical microkeratomes, but long-term results are still needed. ${ }^{3}$ Therefore, refinement of cutting quality with regard to morphology of cutting surfaces and edges is ongoing. A smooth cutting surface is considered to be one of the main quality markers in LASIK. Surface irregularities can cause haze and result in lower visual outcome; furthermore, predictability is reduced because the later excimer laser ablation profile is altered. ${ }^{4,5}$ Sharp cut edges are relevant for the reduction of postoperative epithelial ingrowth, less flap dislocations, and less postoperative inflammation. ${ }^{6-9}$

Today, different instruments can be used for corneal preparation such as occurs in LASIK. One recent option is use of an fs-laser system, ${ }^{10}$ which is, however, a very expensive surgical tool for lamellar keratotomies. Despite the increasing use of fs-lasers, microkeratomes are still common for cutting flaps. ${ }^{3}$

As long as fs-lasers do not offer a main advantage in terms of visual outcome or complications, microkeratomes can continue to be regarded as a cost-saving alternative. Hence it is also necessary to refine the technical parameters of mechanical microkeratomes. In this study, we examined the influence of different oscillation rates, head advances, and cutting depths on the quality of corneal flap cuts.

\section{Materials and methods}

In this experimental study, freshly isolated porcine eyes $(n=32)$ obtained from a local slaughterhouse were used. They were kept in a wet chamber at $4^{\circ} \mathrm{C}$ and used within 5 hours. Prior to surgery, eyes were held at room temperature for 2 hours to allow deswelling of the corneal stroma. Only macroscopically perfect eyes not showing any epithelial defects were used. After removing adnexa (lids, extraocular muscles, and conjunctiva), the eyes were placed in a suction device in which the intraocular pressure was set to $20 \mathrm{mmHg}$ by vacuum.

Flaps were created using the Carriazo-Pendular (CP) microkeratome (SCHWIND eye-tech-solutions $\mathrm{GmbH} \&$ Co, KG, Kleinostheim, Germany). This instrument relies on a pendulum-like cutting action being controlled by a console giving acoustic and visual signs. Surgeons have the opportunity to freely choose the hinge position. Furthermore, different flap diameters from 8 to $10 \mathrm{~mm}$ can be chosen. Blade speed can be set within a range of 2 to $5 \mathrm{~mm} / \mathrm{second}$, and oscillation frequencies can be adjusted from 9,000 to $15,000 \mathrm{rpm}$. Cutting heads of different sizes $(90 \mu \mathrm{m}, 110 \mu \mathrm{m}$, $130 \mu \mathrm{m}, 150 \mu \mathrm{m}$, and $170 \mu \mathrm{m})$ are also available. ${ }^{11}$
Four flap-cut series including eight cuts each were performed. For each cut, a new blade was used. Microkeratome settings were changed so that four different setups (CP 1-4) could be tested (Table 1). Cutting depths and head-advance rates were changed in these four groups. To compare the different head advances, a quotient was created containing the oscillation frequency and head-advance-speed. This quotient was named the oscillation/advance ratio (OAR) in cuts $/ \mathrm{mm}$. With an oscillation frequency of 15,000 rpm, 30,000 cuts per minute or 500 cuts per second were performed, equating to 100 cuts per $\mathrm{mm}$ when a head advance of $5 \mathrm{~mm}$ per second is applied.

After cutting, flaps were lifted using a spatula (G-16193; Geuder AG, Heidelberg, Germany), cut at the hinge, and discarded. The interface was washed with $5 \mathrm{~mL}$ BSS-Solution (Alcon Pharma GmbH, Freiburg im Breisgau, Germany). With an $11 \mathrm{~mm}$ Franceschetti trephinator, the corneal beds, including the cutting edges, were removed from the rest of each globe and prepared for scanning electron microscopy (SEM). The corneas were immediately immersed in 3\% glutaraldehyde, $100 \mathrm{mM}$ hydroxyethyl piperazineethanesulfonic acid (HEPES) (pH 7.4), $1 \mathrm{mM} \mathrm{CaCl}_{2}, 1 \mathrm{mM} \mathrm{MgCl}_{2}$, and $25 \mathrm{mM} \mathrm{NaN}_{3}$ and left at room temperature for 2 hours, and then at $4{ }^{\circ} \mathrm{C}$ overnight. The tissues were treated with $2 \%$ tannic acid for 1 hour, $2 \%$ osmium tetroxide for 2 hours, and $2 \%$ uranyl acetate for 1 hour, with washing steps in between. Afterwards, the samples were dehydrated in a graded series of aqueous ethanol solutions $(20 \%-100 \%)$. This was followed by critical point-drying with amyl acetate and $\mathrm{CO}_{2}$. Finally, samples were mounted on aluminum stubs, sputtered with gold, and examined by SEM in a DSM 940 A (Carl Zeiss AG, Oberkochen, Germany). The description of the morphology of the corneal stromal bed as well as the evaluation of their surface quality was carried out on the basis of the electron micrographs.

For evaluation, a semiquantitative score system was applied to the results observed in the SEM micrographs. ${ }^{12}$

Table I Parameters of the different cutting series

\begin{tabular}{llllll}
\hline Series & $\mathbf{n}$ & $\begin{array}{l}\text { Oscillation } \\
\text { frequency } \\
(\mathbf{r p m})\end{array}$ & $\begin{array}{l}\text { Head } \\
\text { advance } \\
(\mathbf{m m} / \mathbf{s e c o n d})\end{array}$ & $\begin{array}{l}\text { OAR } \\
\text { cuts/mm }\end{array}$ & $\begin{array}{l}\text { Depth of } \\
\text { keratotomy } \\
(\mu \mathrm{m})\end{array}$ \\
\hline CP I & 8 & 15,000 & 3 & 167 & 110 \\
CP 2 & 8 & 15,000 & 3 & 167 & 130 \\
CP 3 & 8 & 15,000 & 3 & 167 & 150 \\
CP 4 & 8 & 15,000 & 5 & 100 & 150 \\
\hline
\end{tabular}

Notes: CP I: 167 cuts/mm and I I $0 \mu \mathrm{m}$ depth of keratotomy; CP 2: 167 cuts/mm and $130 \mu \mathrm{m}$ depth of keratotomy; CP 3: 167 cuts $/ \mathrm{mm}$ and I $50 \mu \mathrm{m}$ depth of keratotomy; CP 4: 100 cuts/mm and $150 \mu \mathrm{m}$ depth of keratotomy.

Abbreviations: CP, Carriazo-Pendular; OAR, oscillation/advance ratio; rpm, rotations per minute. 
Different criteria were evaluated, with points given corresponding to the cutting quality. Therefore, cutting edges (Table 2) and cutting surfaces (Table 3) were evaluated separately. For evaluating the cutting edges, a 100-fold magnification was used. Three different graduations were available (criteria I-III). A clearly visible cutting edge with no irregularities and a sharp epithelial-stromal crossing was scored with 3 points (criterion I). A visible but partly inhomogeneous rim was evaluated as 2 points (criterion II). If the edge was barely locatable, it was evaluated as 1 point (criterion III).

An electron micrograph with ten-fold magnification was used to evaluate the cutting surface (criterion A). Regularity of surface structure (criterion B), portion of surface irregular (criterion C), and position of the irregular area (criterion D) were evaluated on the basis of 50-fold magnification of the sample. Each of the eight specimens per series was scored up to a maximum of 3 points for the evaluation of the cut edges (possible maximum of 24 points) and 11 points for the evaluation of the cut surfaces (possible maximum of 88 points). As we examined eight cuts per setting, a maximum of 112 points could be achieved per series. The evaluation was performed in a blinded manner by two different surgeons.

Statistical analysis was performed using SPSS software (v 16 for Windows; IBM Corporation, Armonk, NY, USA). The Student's $t$-test was applied for comparisons. A $P$-value less than 0.05 was considered to be statistically significant. For each microkeratome setting, the results were averaged and compared using Excel software (Microsoft Corporation, Redmond, WA, USA). Each series consisted of eight cuts. As new blades were used for each keratotomy and a complex preparation for SEM was needed, sample size was limited.

Additionally, morphological features were examined. Cutting shapes were evaluated qualitatively. Typical morphological characteristics of each microkeratome setup are herein described.

\section{Examples of different morphologies}

Different morphologies appeared and were evaluated. Figure 1 summarizes different cutting morphologies that formed the basis for the scoring. Regarding cutting edges, the Carriazo-Pendular microkeratome creates a serrated rim,

Table 2 Criteria for the evaluation of cut edges

\begin{tabular}{lll}
\hline Criterion & Description & Score \\
\hline I & Sharp, clearly visible cutting edge & 3 \\
II & Blurred but visible cutting edge & 2 \\
III & No cutting edge visible & I \\
\hline
\end{tabular}

Table 3 Criteria for the evaluation of cut surface characteristics

\begin{tabular}{|c|c|c|}
\hline Criterion & Appearance & Score \\
\hline A: surface relief, & No visible roughness & 2 \\
\hline I0X magnification & Roughness visible & 1 \\
\hline B: regularity of surface & Almost completely maintained & 3 \\
\hline \multirow[t]{2}{*}{ structure, $50 \times$ magnification } & Partially maintained & 2 \\
\hline & Not maintained & I \\
\hline C: portion of surface irregular, & $<10 \%$ of cut surface & 3 \\
\hline \multirow[t]{2}{*}{$50 \times$ magnification } & $10 \%-20 \%$ of cut surface & 2 \\
\hline & $>25 \%$ of cut surface & I \\
\hline D: position of the irregular & No irregularities & 3 \\
\hline \multirow[t]{2}{*}{ area, $50 \times$ magnification } & Peripheral only & 2 \\
\hline & All over & I \\
\hline
\end{tabular}

showing the typical shape (Figure 1A-a). Another criterion was the visibility of the crossing from the epithelium to the stroma of the cornea (Figure 1A-b). In this area, irregularities such as tissue ruptures appeared (Figure 1A-c). According to the sharpness of the cutting edges, different scores were available (criteria I-III), as shown in Table 2.

The cutting surface was observed with regard to any surface roughness on the basis of ten-fold magnification electron micrograph (Table 3, criterion A). In case of a homogenous surface, the cut scored 2 points. If the surfaces had a nearly completely regular shape, 3 points were awarded. The interface could show waves (Figure 1B-a), tissue roughness (Figure 1B-b), or tissue ruptures (Figure 1B-c). Depending on the location of these irregular morphologies, centrally or peripherally, scores from 1-3 points were assigned.

\section{Results}

A total of 32 cuts were examined. Series 1 to 4 were performed using different microkeratome parameters. No cutting complications, such as free flaps, buttonholes, or incomplete cuts, occurred. Figure 2 shows representative samples of cutting edges and stromal surfaces for each of the series. Scoring of each series is summarized in Figure 3.

\section{Morphology of the stromal bed surface}

The amount of the inhomogeneous areas led to different evaluations, as shown in Table 4 . This was estimated by distribution on the SEM micrographs. The corneal stromal bed demonstrated a very smooth morphology. Evaluating criterion A, which characterized the overall appearance of the interface, there was a tendency toward more irregularities in series CP 1 and 2, with the $110 \mu \mathrm{m}$ and the $130 \mu \mathrm{m}$ cutting head, respectively. The other cutting surface criteria (B-D) were taken together as the regularity index. Series CP 3 and 4 reached the highest scores in terms of this index. 

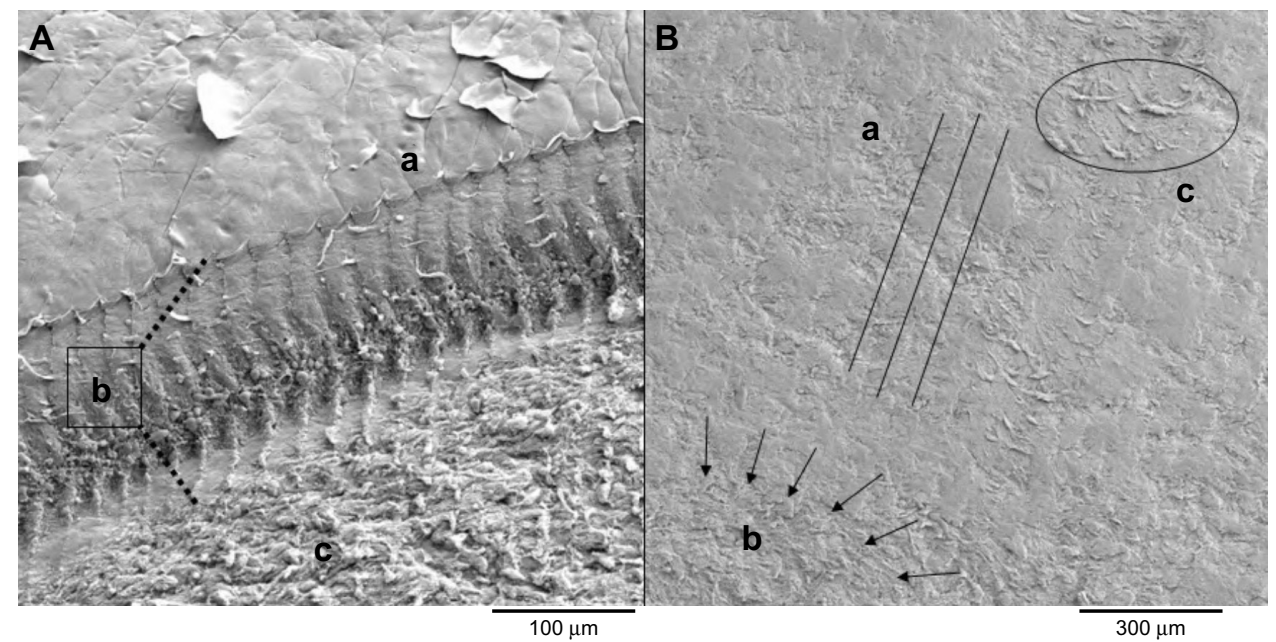

Figure I Examples for cutting morphologies.

Notes: (A) Cutting edge, 100× magnification. (a) Epithelium; (b) epithelial-stromal crossing area; (c) stroma. (B) Cutting surface, 50× magnification. (a) Parallel waves; (b) tissue roughness; (c) tissue ruptures.

More specifically, it was the percentage amount of irregular areas (criterion $\mathrm{C}$ ) and the integrity of the surface regularity (criterion B) that exhibited the main differences.

Comparing the surface scores of the different series, no statistical significance could be shown. Series CP 4 achieved a total of 77 points, equating to $88 \%$ of the theoretically possible maximum points. In comparison, CP 3 scored 72 points $(P=0.407)$ and series CP 1 and 2 scored 65 points each ( $P=0.055$ and $P=0.108$, respectively). Table 4 summarizes the score results for the quality of the stromal bed.

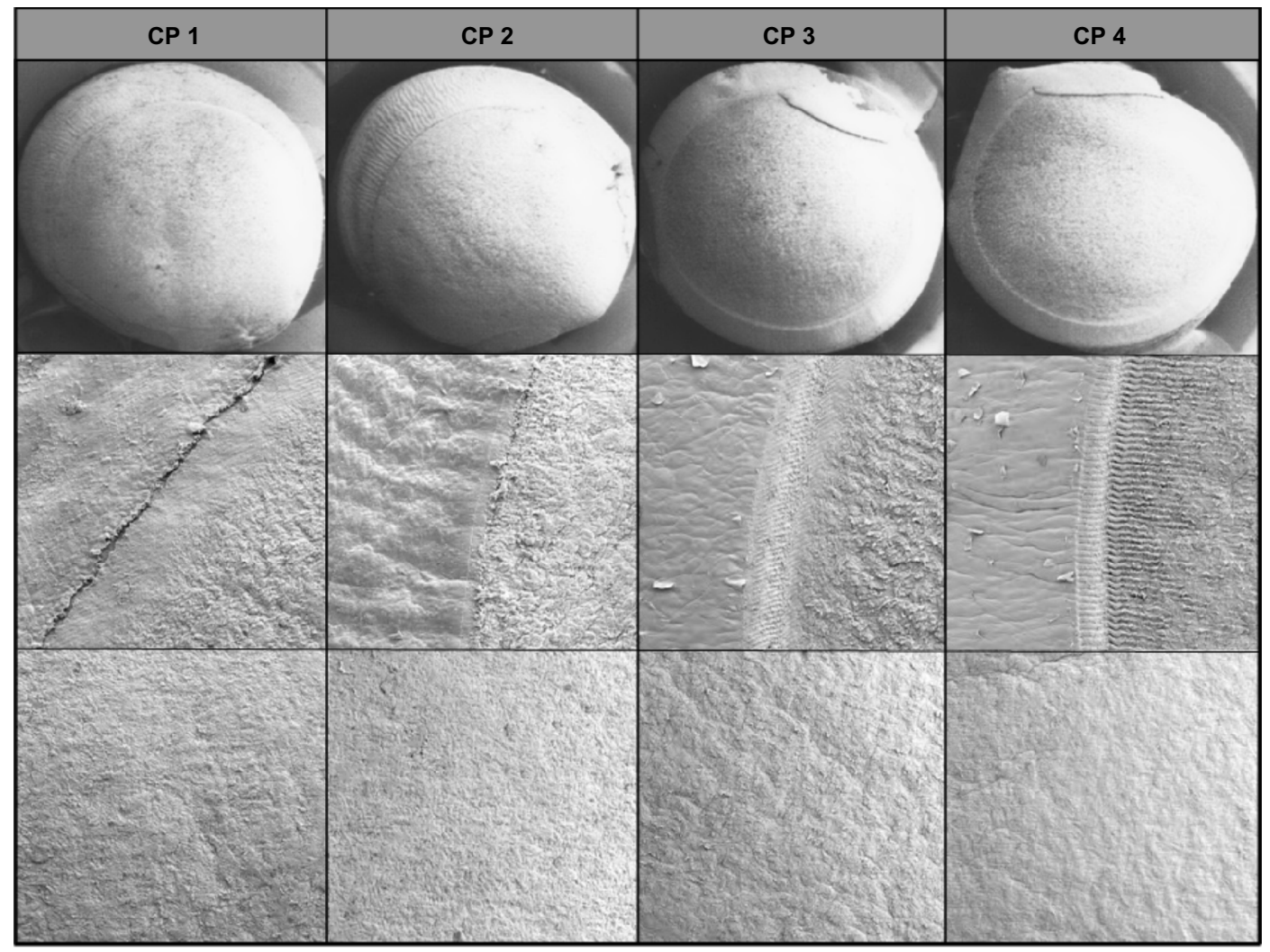

Figure 2 Cutting examples for the series CP I-4.

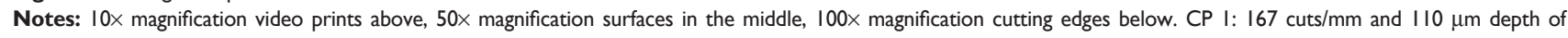
keratotomy; CP 2: 167 cuts $/ \mathrm{mm}$ and I $30 \mu \mathrm{m}$ depth of keratotomy; CP 3: I67 cuts/mm and I50 $\mu \mathrm{m}$ depth of keratotomy; CP 4 : I00 cuts/mm and I50 $\mu \mathrm{m}$ depth of keratotomy. Abbreviation: $\mathrm{CP}$, Carriazo-Pendular. 


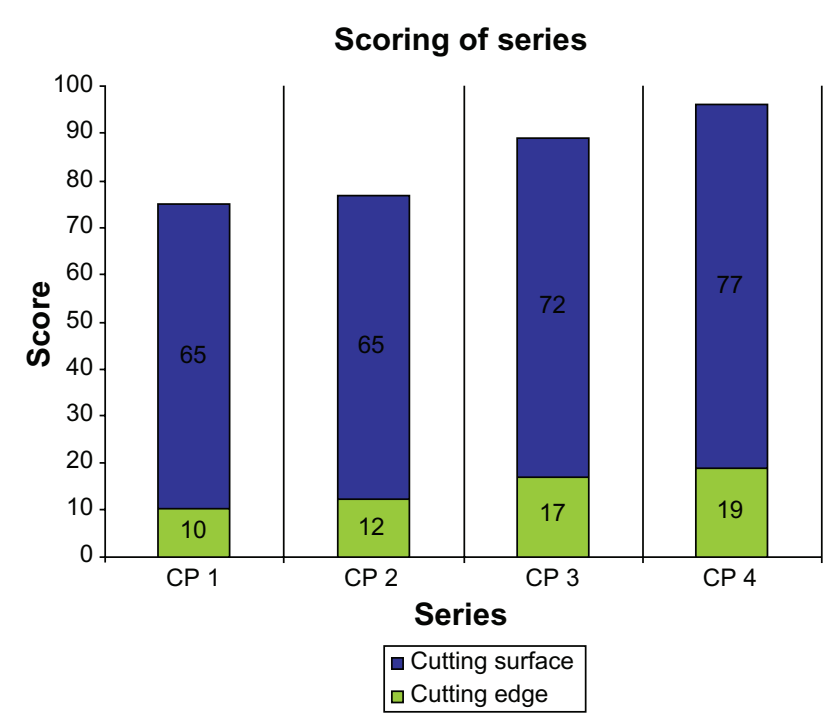

Figure 3 Scoring of series for cutting surfaces (blue bar) and cutting edges (green bar). Notes: CP I: 167 cuts/mm and II0 $\mu \mathrm{m}$ depth of keratotomy; CP 2: 167 cuts/ $\mathrm{mm}$ and $130 \mu \mathrm{m}$ depth of keratotomy; CP 3: $167 \mathrm{cuts} / \mathrm{mm}$ and $150 \mu \mathrm{m}$ depth of keratotomy; CP 4: 100 cuts $/ \mathrm{mm}$ and $150 \mu \mathrm{m}$ depth of keratotomy.

Abbreviation: $\mathrm{CP}$, Carriazo-Pendular.

\section{Morphology of the cutting edges}

The cutting edges showed serrations, as is typical for microkeratomes. The sharpness of the transition between epithelium and stroma, in particular, was inspected. Furthermore, tissue bridges in that area were surveyed. Comparing the four series with their different cutting heads, deeper keratotomies led to a sharper cutting edge. The $150 \mu \mathrm{m}$ cutting head (series CP 3 and 4) scored significantly higher than the $110 \mu \mathrm{m}$ cutting head used in series CP $1(P<0.05)$. The group with a higher blade cutting rate $(\mathrm{CP} 4)$ also scored slightly higher. The thinner the keratotomies, the more irregularities appeared at the cutting edges. Table 5 summarizes the score results of each series.

\section{Impact of keratotomy depth and OAR on scoring results}

Our investigations revealed that different head-advance speeds and different cutting heads did not influence the surface of the

Table 4 Scoring of the surface evaluation

\begin{tabular}{llllll}
\hline Series & \multicolumn{2}{l}{$\begin{array}{l}\text { Criteria with scores (mean score } \\
\text { per series), } \mathbf{n = 8}\end{array}$} & \multirow{2}{*}{ Total } \\
\cline { 2 - 5 } & $\mathbf{A}$ & $\mathbf{B}$ & $\mathbf{C}$ & $\mathbf{D}$ & \\
\hline CP I & $10(1.25)$ & $21(2.625)$ & $18(2.25)$ & $16(2.0)$ & $65(8.125)$ \\
CP 2 & $10(1.25)$ & $20(2.5)$ & $20(2.5)$ & $15(1.875)$ & $65(8.125)$ \\
CP 3 & $15(1.875)$ & $23(2.875)$ & $20(2.5)$ & $14(1.75)$ & $72(9.0)$ \\
CP 4 & $16(2.0)$ & $23(2.875)$ & $21(2.625)$ & $17(2.125)$ & $77(9.625)$ \\
\hline
\end{tabular}

Notes: CP I: 167 cuts $/ \mathrm{mm}$ and I $10 \mu \mathrm{m}$ depth of keratotomy; CP 2: 167 cuts/mm and $130 \mu \mathrm{m}$ depth of keratotomy; CP 3: 167 cuts/mm and I $50 \mu \mathrm{m}$ depth of keratotomy; CP 4: 100 cuts $/ \mathrm{mm}$ and $150 \mu \mathrm{m}$ depth of keratotomy. A: Surface relief; B: regularity of surface structure; C: portion of irregular surface; D: position of the irregular area. Abbreviation: $\mathrm{CP}$, Carriazo-Pendular.
Table 5 Scoring of the cutting edge evaluation

\begin{tabular}{lllll}
\hline Series & \multicolumn{2}{l}{ Criterion } & & Total \\
\cline { 2 - 4 } & I & II & III & \\
\hline CP I & 6 & 4 & 0 & 10 \\
CP 2 & 4 & 8 & 0 & 12 \\
CP 3 & 2 & 6 & 9 & 17 \\
CP 4 & 0 & 10 & 9 & 19 \\
\hline
\end{tabular}

Notes: $\mathrm{CP}$ I: $167 \mathrm{cuts} / \mathrm{mm}$ and I $10 \mu \mathrm{m}$ depth of keratotomy; CP 2: $167 \mathrm{cuts} / \mathrm{mm}$ and $130 \mu \mathrm{m}$ depth of keratotomy; CP 3: 167 cuts $/ \mathrm{mm}$ and I $50 \mu \mathrm{m}$ depth of keratotomy; CP 4: 100 cuts $/ \mathrm{mm}$ and $150 \mu \mathrm{m}$ depth of keratotomy. I: Sharp, clearly visible cutting edge; II: blurred but visible cutting edge; III: no cutting edge visible.

Abbreviation: $\mathrm{CP}$, Carriazo-Pendular.

keratotomies significantly, although there was a trend toward better surface quality using cutting heads performing a deeper keratotomy (Figure 4B). Further, higher head-advance speeds (lower OAR) seemed to be advantageous for a smoother interface. As such, we observed a higher surface regularity in the series with $5 \mathrm{~mm} /$ second advance speed (Figure 4A). This trial was scored 77 points, whereas the same settings, except with a $3 \mathrm{~mm} / \mathrm{second}$ head advance, scored 72 points. Overall, the scores of the different series ranged from 65 to 77 points (theoretical maximum 88 points). On the basis of scanning electron micrographs, certain surface morphologies, such as tissue ruptures or parallel waves, could be visualized. The reproducibility increased with the depths of keratotomy. Changing the cutting heads from $110 \mu \mathrm{m}$ over $130 \mu \mathrm{m}$ to 150 $\mu \mathrm{m}$, the standard deviation decreased $( \pm 0.77$ over \pm 0.73 to \pm 0.66 ). The surface scored a mean of 8.125 points for the $110 \mu \mathrm{m}$ and $130 \mu \mathrm{m}$ cutting head. The $150 \mu \mathrm{m}$ head scored 9 points (theoretical maximum of 11 points). After reducing the OAR, the score and standard deviation decreased $(9.625$ and \pm 0.55 , respectively).

\section{Discussion}

The LASIK procedure is a highly standardized and automated surgical procedure. Involved instruments have to provide a maximum of safety, accuracy, and simplicity with regards to handling and performance. Different steps of the surgery may have an impact on visual outcome. The preparation of the flap and its quality is of particular importance. This study showed morphologic characteristics of keratotomies performed by the Carriazo-Pendular, a modern mechanical microkeratome. Different cutting parameters affected the morphology of the cuts. This study assessed the influence of variable depths of keratotomies and different head-advance speeds while using a constant oscillation frequency.

The Carriazo-Pendular microkeratome offers a unique and modern design for preparation of lamellar keratotomies such as LASIK or Descemet's stripping automated 
A

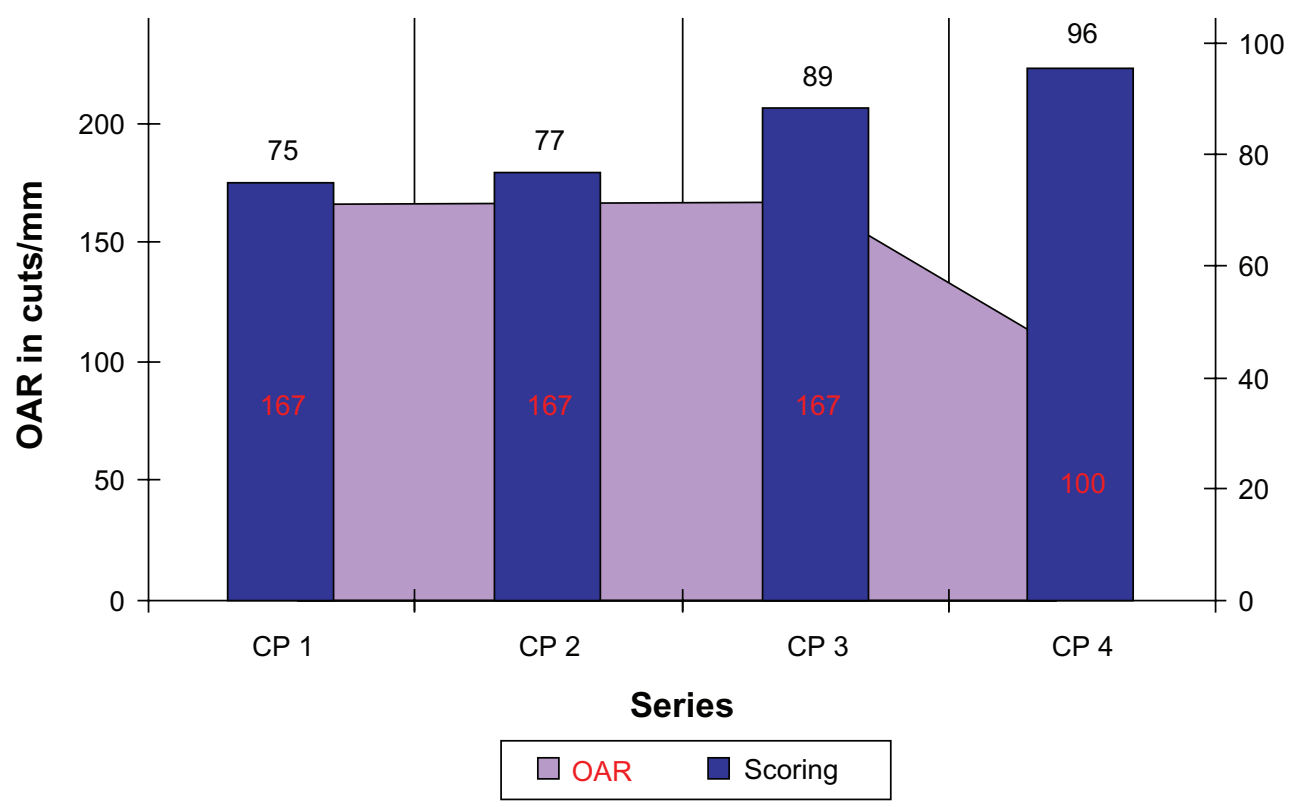

B Impact of depth of keratotomy

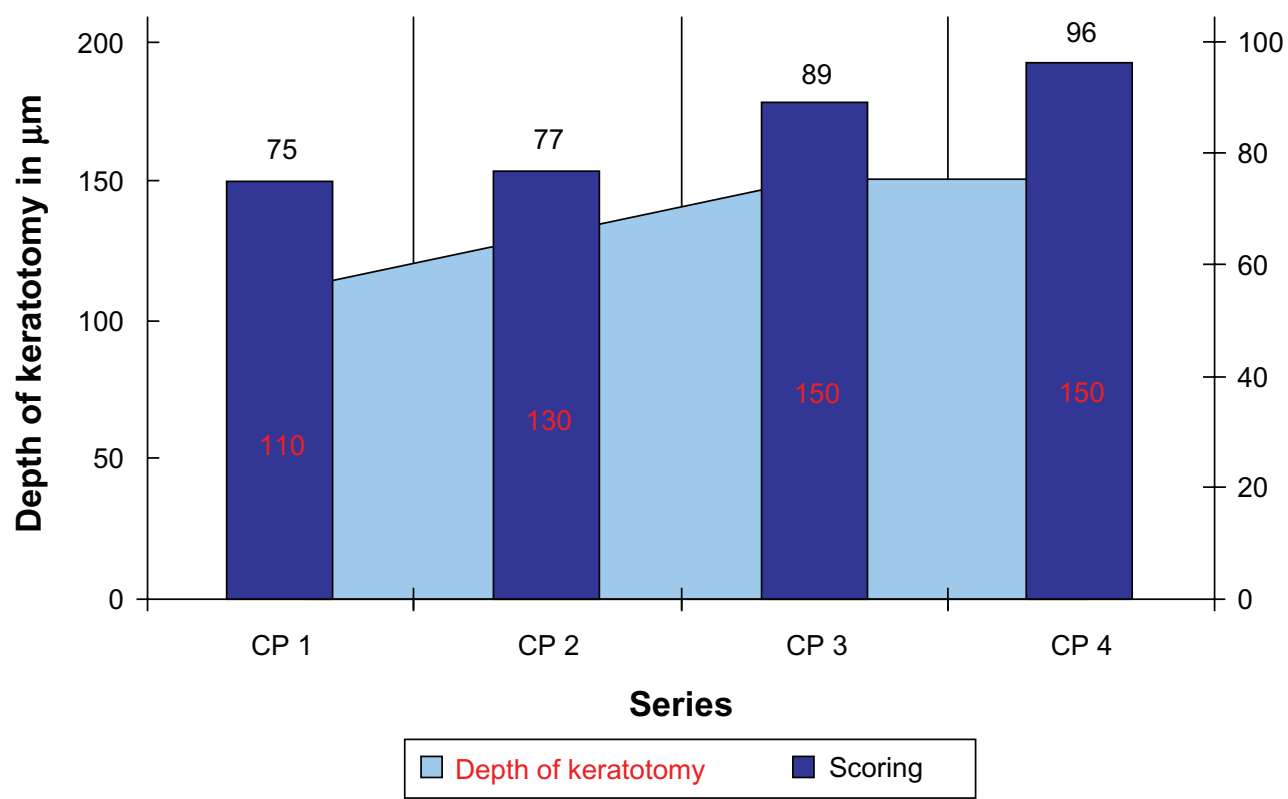

Figure 4 Impact of depth of keratotomy $(\mathbf{A})$ and oscillation/advance ratio (OAR) (B) on scoring results.

Notes: CP I: 167 cuts $/ \mathrm{mm}$ and I I0 $\mu \mathrm{m}$ depth of keratotomy; CP 2: 167 cuts $/ \mathrm{mm}$ and I $30 \mu \mathrm{m}$ depth of keratotomy; CP 3: I67 cuts/mm and I50 $\mu \mathrm{m}$ depth of keratotomy; CP 4: 100 cuts/mm and $150 \mu \mathrm{m}$ depth of keratotomy. Black numbers include scoring for cutting surfaces and cutting edges; red numbers show OAR (A) and depth of keratotomy (B).

Abbreviation: CP, Carriazo-Pendular.

endothelial keratoplasty (DSAEK). It is one of the most used devices for mechanical flap preparation in LASIK procedure in Germany. ${ }^{13}$ An advantage is its special type of cutting (molding technique). Realized by the cutting head design fulfilling a convex applanation of the cornea, the created flap shows a planar configuration. ${ }^{11,14}$ This offers advantages for the later ablation by the excimer laser. Because of the constant pressure on the cornea, fewer buttonholes appear. ${ }^{15}$ 
A homogenous stromal surface after flap preparation leads to better visual outcome, and high oscillation frequencies combined with a fast blade rate lead to higher reproducibility, ${ }^{4,5}$ while an elevation of head advance using the same oscillation frequencies created worse surface qualities. Using lower OARs, better cutting results were observed. ${ }^{16}$ Higher oscillation frequencies combined with lower advance speed possibly increases the horizontal tissue dislocation because of more blade movement without real cutting the collagen fibers. On the other hand, if the head advancement per oscillation is lower, the tissue is cut more cleanly and with less dragging and chattering. ${ }^{17}$ Contrary to our results, no influence of different head advance speeds on the interface smoothness has been previously revealed in porcine eyes. ${ }^{18}$

Characteristic serrations have been observed on the cutting edges, as described in earlier studies. ${ }^{12,19}$ Reducing the cutting depth, the edge configuration becomes increasingly blurred. This may lead to more flap-associated complications. The trial series with the $110 \mu \mathrm{m}$ head $(3 \mathrm{~mm} / \mathrm{second}$ head advance) was scored 10 out of the theoretical maximum of 24 points (42\%). In comparison to the $150 \mu \mathrm{m}$ head ( $3 \mathrm{~mm} / \mathrm{second}$ head advance), the score decreased significantly $(P<0.05)$. A cutting head of $130 \mu \mathrm{m}$ scored 12 points, which is $50 \%$ of the theoretical maximum. Deeper keratotomy enables safer blade movement in the corneal stroma. Varying the head advance did not affect the cutting edge quality significantly, but there was a trend toward better results in the trial using $5 \mathrm{~mm} /$ second head advance; here, 19 of 24 points were achieved (79\%). The series with $3 \mathrm{~mm} / \mathrm{second}$ scored 17 of 24 points $(71 \%)$. To our knowledge, clinical studies proving the impact of keratotomy depth on postoperative complications such as flap dislocation are not available to date. Nevertheless, it is essential to leave a residual stromal thickness of at least $250 \mu \mathrm{m}$ after cutting and laser ablation in order to avoid iatrogenous corneal ectasia. It would be desirable to investigate the lowest cutting depth with which cutting edges present the best morphology. ${ }^{20}$

Sarayba et al investigated nine human corneas using SEM micrographs and showed a smoother stromal bed after application of a $30 \mathrm{kHz}$ fs-laser when flaps with $110 \mu \mathrm{m}$ thickness were created. ${ }^{21}$ This may have been due to the fact that they used human corneas and different parameters of photodisruptive preparation technique. Therefore, the results are not directly comparable. It seems very probable that fs-lasers can generate smoother cutting surfaces, although thinner flaps are created. The small sample size in Sarayba et al's study reduces its validity. ${ }^{21}$ In this context, fs-lasers might be advantageous over microkeratomes as they can produce very thin flaps while the cutting edges remain extremely sharp. ${ }^{22}$

Porcine corneas are established models simulating human tissue; ${ }^{12,19,22,23}$ however, it would have been desirable to investigate human eyes because there are ultrastructural differences that limit the comparability of both tissues. The human cornea, having a strictly organized Bowman's layer, is more rigid. As the porcine corneal tissue is smoother it might visualize cutting characteristics better. ${ }^{24}$ Considering this aspect, porcine eyes could be regarded as a sensitive model showing the characteristics of LASIK instruments on surface quality of the cuts. In contrast, there are investigations demonstrating more surface irregularities in human corneas than in porcine corneas. ${ }^{18}$ The animal model can serve its purpose for investigation of different technical parameters, especially since large numbers of samples are available. Correlation between system settings and morphology can be shown in animal studies. Further investigations must prove such results in regard to the clinical outcome in humans. The next step could be in situ investigations, such as in the study of Ramírez et al, who studied reflective particles in the interface after either bilateral LASIK by fs-laser or microkeratome on one eye using confocal microscopy, found that there was no statistically significant difference in the numbers of particles between each eye. ${ }^{25}$

The scoring system used in this study provided a very detailed description of cutting quality, but depended on the subjective evaluation of the surgeons. To avoid this bias, it would be better to have software detecting and evaluating the different criteria.

The aim of correcting higher myopia requires the creation of thinner flaps. Iatrogenic keratectasia is an ongoing problem, even if the residual stroma thickness is more than $300 \mu \mathrm{m} .{ }^{26,27}$ The preparation of ultrathin flaps may lead to problems like microstriae, tissue particle dislocation into the interface, or flap dislocation. ${ }^{11,26} \mathrm{~A}$ sharp cutting edge is regarded as advantageous, avoiding corneal erosion, epithelial ingrowth into the interface, and scarring, as well as flap dislocation. ${ }^{19}$ Serrations of the cutting edge could further support the flap adaptation. The steeper the cut, the less epithelial cells are altered, which could decrease epithelial ingrowth and unreasonably wound healing reaction. Stronger tissue alteration caused by blurred cutting can cause more inflammation leading to stronger scaring as well as myopic regression. ${ }^{7,9}$ Additionally, the cutting head design has an important effect concerning the development of epithelial defects. ${ }^{8}$

Another possible application for microkeratomes is the preparation of corneal grafts for DSAEK, in which it 
is desirable to create a thin and homogenous lenticule for transplantation. The Carriazo-Pendular microkeratome device in combination with an artificial anterior chamber is available for this type of surgery. In comparison to fs-laser-assisted preparation, the microkeratome seemed to be superior in regards to postoperative visual outcome. ${ }^{28,29}$ Further developments in DSAEK are made in creating an ultrathin flap by a microkeratome. After a first cut of $300 \mu \mathrm{m}$, a second cut formed a $100 \mu \mathrm{m}$ lenticule, which is used for DSAEK. With this technique, comparable visual outcomes to Descemet's membrane endothelial keratoplasty could be reached, requiring less time and with fewer difficulties with donor tissue preparation. ${ }^{30-32}$ Good cutting results while preparing deeper keratotomies, in particular, could be advantageous. A reason for the better outcome after microkeratome preparation in comparison to fs-laser preparation might be less tissue bridges. ${ }^{23,33}$

Material and equipment costs play an important role in daily medical routine. Microkeratomes such as the CarriazoPendular device could be a cost-saving alternative to the very expensive and vulnerable fs-laser devices. In a prospective randomized clinical study of visual outcome, higher-order aberrations and flap thicknesses of fellow eyes treated with fs-laser- or mechanical keratome-created flaps during laser in situ keratomileusis in myopes was investigated. ${ }^{34}$ Besides more predictable flap thicknesses in the fs-laser group, there were no significant differences concerning visual outcome, whereas higher-order aberrations were lower in the microkeratome group. In a meta-analysis, similar conclusions were drawn: both kinds of preparations revealed comparable safety and efficacy. There were more epithelial defects after microkeratome use, but more cases of deep lamellar keratitis after fs-laser application. ${ }^{10}$

A deeper keratotomy enables a safer sliding of the blade in the corneal stroma. This may avoid postoperative complications such as flap dislocation. The sharper cutting edges might be more important for LASIK than for DSAEK. Higher oscillation frequencies may increase the horizontal tissue scattering. Each microkeratome system should be regarded as a whole functional unit. The investigation of single parameters is very difficult. Therefore, the declaration of an OAR for each instrument might be helpful.

\section{Conclusion}

Microkeratomes may offer a cost-saving alternative to fslasers. It still remains a wide field for indications for microkeratome use such as LASIK or DSAEK. Further studies should compare both techniques to provide more information about their advantages and disadvantages.

\section{Disclosure}

The authors report no conflicts of interest in this work. None of the authors has any financial or proprietary interest in any material or method mentioned.

\section{References}

1. Lamparter J, Dick HB, Krummenauer F. Clinical benefit, complication patterns and cost effectiveness of laser in situ keratomileusis (LASIK) in moderate myopia: results of independent meta analyses on clinical outcome and postoperative complication profiles. Eur J Med Res. 2005;10(9):402-409.

2. Lamparter J, Dick H, Krummenauer F. Komplikationen nach Laser-in-Situ-Keratomileusis (LASIK). Ergebnisse einer Metaanalyse zu Inzidenzen und Folgekosten [Complications after laser in situ keratomileusis (LASIK). Results of a meta-analysis of incidence and followup costs]. Klin Monbl Augenheilkd. 2007;224:627-635. German.

3. Farjo AA, Sugar A, Schallhorn SC, et al. Femtosecond lasers for LASIK flap creation: a report by the American Academy of Ophthalmology. Ophthalmology. 2013;120(3):e5-e20.

4. Vinciguerra P, Azzolini M, Airaghi P, Radice P, De Molfetta V. Effect of decreasing surface and interface irregularities after photorefractive keratectomy and laser in situ keratomileusis on optical and functional outcomes. J Refract Surg. 1998;14(Supp1 2):S199-S203.

5. Hoffmann S, Krummenauer F, Tehrani M, Dick HB. Impact of head advance and oscillation rate on the flap parameter: a comparison of two microkeratomes. Graefes Arch Clin Exp Ophthalmol. 2003;241: 149-153.

6. Haw WW, Manche EE. Late onset diffuse lamellar keratitis associated with an epithelial defect in six eyes. J Refract Surg. 2000;16:744-748.

7. Asano-Kato N, Toda I, Hori-Komai Y, Takano Y, Tsubota K. Epithelial ingrowth after laser in situ keratomileusis: clinical features and possible mechanisms. Am J Ophthalmol. 2002;134:801-807.

8. Kohnen T, Terzi E, Mirshani A, Buhren J. Intraindividual comparison of epithelial defects during laser in situ keratomileusis using standard and zero-compression Hansatome microkeratome heads. J Cataract Refract Surg. 2004;30:123-126.

9. Oliva MS, Ambrósio Júnior R, Wilson SE. Influence of intraoperative epithelial defects on outcomes in LASIK for myopia. Am J Ophthalmol. 2004;137:244-249.

10. Chen S, Feng Y, Stojanovic A, Jankov MR 2nd, Wang Q. IntraLase femtosecond laser vs mechanical microkeratomes in LASIK for myopia: a systematic review and meta-analysis. J Refract Surg. 2012; 28(1):15-24.

11. Arbelaez MC. The Schwind Carriazo-Pendular microkeratome. Techniques in Ophthalmology. 2007;5:138-142.

12. Wilhelm FW, Giessmann T, Hanschke R, Duncker GIW, Wilhelm LH. Cut edges and surface characteristics produced by different microkeratomes. J Refract Surg. 2000;16:690-700.

13. Schmack I, Auffarth GU, Epstein D, Holzer MP. Refractive surgery trends and practice style changes in Germany over a 3-year period. J Refract Surg. 2010;26:202-208.

14. Alio JL, Pinero DP. Very high-frequency digital ultrasound measurement of the LASIK flap thickness profile using the IntraLase femtosecond laser and M2 and Carriazo-Pendular microkeratomes. $J$ Refract Surg. 2008;24:12-23.

15. Gimbel HV, Penno EE, van Westerbrugge JA, Ferensowicz M, Furlong MT. Incidence and management of intraoperative and early postoperative complications in 1000 consecutive laser in situ keratomileusis cases. Ophthalmology. 1998;105:1839-1847; discussion 1847-1848. 
16. Tehrani M, Schäfer S, Dick HB. Evaluation of cut quality using the Amadeus microkeratome with different settings. J Cataract Refract Surg. 2004;30:2415-2419.

17. Draeger J, Böhnke M, Grabner G, Slezak H, Lang K. New methods of refractive corneal surgery. Experimental studies. Klin Monbl Augenheilkd. 1988:192(5):458-61.

18. Sanka RK, Loft ES, Randleman JB. Effect of varying microkeratome parameters on laser in situ keratomileusis interface surfaces. J Cataract Refract Surg. 2010;36:493-496.

19. Hammer T, Hanschke R, Wörner I, Wilhelm FW. Evaluation of four microkeratome models: quality and reproducibility of cut edge and cut surface as determined by scanning electron microscopy. J Refract Surg. 2005;21:454-462.

20. Joo CK, Kim TG. Corneal ectasia detected after laser in situ keratomileusis for correction of less than -12 diopters of myopia. J Cataract Refract Surg. 2000;26:292-295.

21. Sarayba MA, Ignacio TS, Binder PS, Tran DB. Comparative study of stromal bed quality by using mechanical, IntraLase femtosecond laser 15- and 30-kHz microkeratomes. Cornea. 2007;26:446-451.

22. Heichel J, Hammer T, Sietmann R, Duncker GI, Wilhelm F. [Scanning electron microscopic characteristics of lamellar keratotomies using the Femtec femtosecond laser and the Zyoptix XP microkeratome. A comparison of quality]. Ophthalmologe. 2010;107(4):333-340. German.

23. Heichel J, Blum M, Duncker GI, Sietmann R, Kunert KS. Surface quality of porcine corneal lenticules after femtosecond lenticule extraction. Ophthalmic Res. 2011;46(2):107-112.

24. Sanchez I, Martin R, Ussa F, Fernandez-Bueno I. The parameters of the porcine eyeball. Graefes Arch Clin Exp Ophthalmol. 2011; 249(4):475-482.

25. Ramírez M, Hernández-Quintela E, Naranjo-Tackman R. A comparative confocal microscopy analysis after LASIK with the IntraLase femtosecond laser vs Hansatome microkeratome. J Refract Surg. 2007;23(3):305-307.
26. Kymionis GD, Portaliou DM, Tsiklis NS, Panagopulou SI, Pallikaris IG. Thin LASIK flap creation using the SCHWIND CarriazoPendular microkeratome. J Refract Surg. 2009;25:33-36.

27. Li H, Sun T, Wang M, Zhao J. Safety and effectiveness of thin-flap LASIK using a femtosecond laser and microkeratome in the correction of high myopia in Chinese patients. J Refract Surg. 2010;26:99-106.

28. Vetter JM, Holtz C, Vossmerbaeumer U, Pfeiffer N. Irregularity of the posterior corneal surface during applanation using a curved femtosecond laser interface and microkeratome cutting head. J Refract Surg. 2012;28(3):209-214.

29. Vetter JM, Butsch C, Faust M, et al. Irregularity of the posterior corneal surface after curved interface femtosecond laser-assisted versus microkeratome-assisted descemet stripping automated endothelial keratoplasty. Cornea. 2013;32(2):118-124.

30. Busin M, Madi S, Santorum P, Scorcia V, Beltz J. Ultrathin descemet's stripping automated endothelial keratoplasty with the microkeratome double-pass technique: two-year outcomes. Ophthalmology. 2013;120(6):1186-1194.

31. Maier AK, Gundlach E, Klamann MK, et al. [Influence of donor lamella thickness on visual acuity after Descemet's stripping automated endothelial keratoplasty (DSAEK)]. Ophthalmologe. Epub April 12, 2013 German.

32. Rosa AM, Silva MF, Quadrado MJ, Costa E, Marques I, Murta JN. Femtosecond laser and microkeratome-assisted Descemet stripping endothelial keratoplasty: first clinical results. $\mathrm{Br} J$ Ophthalmol. 2013;97(9):1104-1107.

33. Heinzelmann S, Maier P, Böhringer D, Auw-Hädrich C, Reinhard T. Visual outcome and histological findings following femtosecond laser-assisted versus microkeratome-assisted DSAEK. Graefes Arch Clin Exp Ophthalmol. 2013;251(8):1979-1985.

34. Baily C, Brosnan G, O'Keefe M. Femtosecond laser compared with a mechanical keratome for LASIK in myopes. Journal of Emmetropia. 2012;3:73-81
Clinical Ophthalmology

\section{Publish your work in this journal}

Clinical Ophthalmology is an international, peer-reviewed journal covering all subspecialties within ophthalmology. Key topics include: Optometry; Visual science; Pharmacology and drug therapy in eye diseases; Basic Sciences; Primary and Secondary eye care; Patient Safety and Quality of Care Improvements. This journal is indexed on

\section{Dovepress}

PubMed Central and CAS, and is the official journal of The Society of Clinical Ophthalmology (SCO). The manuscript management system is completely online and includes a very quick and fair peer-review system, which is all easy to use. Visit http://www.dovepress.com/ testimonials.php to read real quotes from published authors. 